Diego Borges de Carvalho' Maria Eleusa Montenegro ${ }^{2}$

\section{O perfil do estudante do curso de licenciatura em Letras e sua preparação para o exercício da docência}

\section{The profile of students of Language Teaching teachers' training courses and their preparation for teaching}

\section{Resumo}

O presente artigo é resultado de uma pesquisa de iniciação científica que se propôs a traçar um perfil do estudante de licenciatura em Letras e verificar sua preparação para o exercício da docência. Utilizou-se como metodologia a abordagem qualitativa e, para a coleta de dados, usou-se um roteiro de entrevista semiestruturado, aplicado a 11 estudantes de Letras de três instituições de ensino superior de Brasília, Distrito Federal. Os resultados demonstraram um estudante de Letras insatisfeito com seu curso e com significativa desmotivação para atuação na Educação Básica, insatisfação essa causada pelos baixos salários e pelas condições escassas de trabalho que o ensino brasileiro oferece.

Palavras-chave: Licenciatura. Formação do professor. Estudante de Letras.

\begin{abstract}
This article is the result of a scientific initiation research that attempted to draw a profile of students of Language Teaching teachers' training courses and to check their preparation for teaching. The methodology used was the qualitative approach, and the instrument of data collection was a semi-structured interview, applied to 11 students of Language Teaching training courses from three institutions of Higher Education in Brasília, Federal District. The results showed students dissatisfied with their course, and significantly disincentived to work in basic education, this feeling caused by low salary and poor working conditions that Brazilian education offers.
\end{abstract}

Keywords: Teachers' training courses. Formation of teachers. Students of Language Teaching courses.

\footnotetext{
1 Acadêmico de Graduação em Letras/Português e bolsista institucional de Iniciação Científica do Centro Universitário de Brasília (UniCEUB). Endereço eletrônico: diegobcar@gmail.com

2 Doutora em Educação pela UNICAMP, PósDoutora pela UnB e professora do Centro Universitário de Brasília (UniCEUB). Endereço eletrônico: memontenegro@terra.com.br
} 


\section{Introdução}

A formação acadêmica de professores tem sofrido, com o passar dos anos, significativas modificações. A pouca procura de candidatos pelos cursos de licenciatura, por motivos de desvalorização da profissão - inclusive financeiro -, é motivo de preocupação para os profissionais comprometidos com a educação no Brasil. A redução do tempo de duração dos cursos de licenciatura constitui outro ponto que compromete a qualidade da formação de docentes.

No que se refere ao curso de Letras, cujo alicerce está na leitura, traçar um perfil e verificar a preparação do acadêmico para a docência é fundamental para melhor entender esse estudante, visando ampliar sua formação e já almejando sua atuação competente no meio social, como futuro formador de profissionais. Nesse sentido, estudo realizado por Benevides (2010), da Universidade Estadual do Rio Grande do Norte, vêm mostrando que é necessário que as universidades formem professores reflexivos e conscientes de seus papéis como leitores e produtores de textos frente a uma sociedade carente do hábito da leitura.

\section{Pressupostos teóricos}

\subsection{Formação de professores e licenciatura em Le- tras}

A licenciatura constitui um grau universitário que permite o exercício do magistério em escolas de Educação Básica. No Brasil, os cursos de licenciatura são pouco procurados pelos vestibulandos por motivos que o próprio meio social impõe. É muito comum, ao optar por um curso de licenciatura como formação acadêmica, ouvir frases de estranheza e ironia como: "Você vai ser professor?", "Boa sorte!" ou "Coitado, não queria estar em sua pele", e "Não tenho paciência”. Isso se deve ao fato de a sociedade ainda não reconhecer a importância da educação para o crescimento de um país.

A formação acadêmica de professores passa, na atualidade, por um processo merecedor de reflexão, pois, pela pouca procura da profissão, as autoridades não encontram outra maneira de estimular a sua busca a não ser a diminuição do tempo da graduação - o que induz o acadêmico a querer apenas o certificado de nível superior, sem a preocupação com o exercício deste aprendizado. Pesquisa realizada pela Fundação Carlos Chagas (MA-
GISTÉRIO, 2010) demonstra que apenas $2 \%$ dos vestibulandos optam por cursos de licenciatura - índices preocupantes para o ensino brasileiro. Essa pesquisa mostrou, ainda, que desde a década de 70, quando começou uma acelerada massificação do ensino público, cresceu bastante o desprestígio do professor, pois, em virtude do número de profissionais não suprir a demanda, as escolas recorreram a pessoas leigas para ministrar aulas.

No tocante ao curso de Letras, o profissional formado deve ter: domínio e visão crítica da linguagem verbal no contexto oral e escrito; conhecimento e habilidades para desempenhar suas funções como formador de opinião. Nesse sentido, o Parecer 492/2001 do Conselho Nacional de Educação (CNE) do Ministério da Educação (BRASIL, 2001b) foi enriquecedor para este trabalho, pois propôs as diretrizes curriculares nacionais do curso de Letras. Tem-se, ainda, o Parecer 9/2001, também do $\mathrm{CNE}$, que diz respeito às diretrizes curriculares nacionais para formação de professores da Educação Básica, que serviu também de parâmetro para o presente estudo (BRASIL, 2001a).

\subsection{Parecer 9/2001 do Conselho Nacional de Educa- ção - CNE}

O Parecer 9/2001 (BRASIL, 2010a) do Conselho Nacional de Educação trata das diretrizes para formação de professores da Educação Básica, em curso de nível superior. Com o Brasil cada dia mais participando da economia mundial e ganhado respeito no mundo, as preocupações devem, sobretudo, estar voltadas para a educação, área a ser reconhecida pela importância que exerce no desenvolvimento sustentável e na diminuição das desigualdades sociais.

Para que haja uma educação de qualidade, são encontradas inúmeras dificuldades, em que se destaca o preparo inadequado dos professores, cuja formação, de maneira geral manteve-se em formato tradicional, sem incorporar os avanços da modernidade. Muitas são as características inerentes à atividade docente:

Orientar e mediar o ensino para a aprendizagem dos alunos; comprometer-se com o sucesso da aprendizagem dos alunos; assumir e saber lidar com a diversidade existente entre os alunos; incentivar atividades de enriquecimento cultural; desenvolver práticas investigativas; elaborar e executar projetos para desenvolver conteúdos curriculares; utilizar novas metodologias, estratégias e materiais de apoio; desenvolver hábitos de colaboração e trabalho em equipe (BRASIL, 2001a, p. 4). 
O processo de elaboração das diretrizes curriculares para graduação solidificou a formação em três categorias (bacharelado acadêmico, bacharelado profissionalizante e licenciatura). Nesse cenário, a licenciatura ganhou terminalidade e integridade própria em relação ao bacharelado, o que exigiu a definição de currículo próprio.

Portanto, para transformar as propostas da Educação Básica em realidade, é necessária uma reforma escolar que conceba a educação como tendo papel fundamental no desenvolvimento das pessoas, a fim de que essas acompanhem as transformações, sobretudo tecnológicas, que trazem grandes mudanças em todos os campos da atividade humana. Com relação aos estudantes de Ensino Fundamental e Médio, é preciso estimulá-los a valorizar os conhecimentos e bens culturais. É também necessário que os alunos aprendam a confrontar e respeitar diferentes pontos de vista. Além disso, é importante que saibam ler criticamente diferentes tipos de texto, utilizar diferentes recursos tecnológicos, expressar-se e comunicar-se em várias linguagens, opinar, enfrentar desafios, criar, agir de forma autônoma e que sejam capazes de diferenciar o espaço público do espaço privado, ser solidários, cooperativos, conviver com a diversidade, repudiar qualquer tipo de discriminação e injustiça.

O referido documento apresenta, ainda, ideias relativas às questões enfrentadas na formação de professores e referentes ao campo institucional e curricular, em que o bacharelado é percebido como uma opção natural e a licenciatura aparece como opção residual "inferior" e "vocacional".

No campo institucional, uma das principais dificuldades é o tratamento inadequado dos conteúdos. Aqui, o professor deve ter domínio dos conteúdos das áreas do conhecimento que serão objeto da sua atuação didática, do contexto em que se inscrevem e das temáticas transversais ao currículo escolar - transposição didática (conteúdos e estratégias):

\begin{abstract}
É preciso indicar com clareza para o aluno qual a relação entre o que está aprendendo na licenciatura e o currículo que ensinará no segundo segmento do ensino fundamental e no ensino médio (BRASIL, 2010a, p. 21).
\end{abstract}

A falta de oportunidade para o desenvolvimento cultural e a concepção restrita de prática constituem outro ponto, pois o professor deve ter uma sólida e ampla formação cultural para a construção da cidadania do aluno, além de saber valorizar os conhecimentos teóricos e acadêmicos, bem como os práticos, como importante fonte de formação.

\subsection{0 estudante universitário de Letras e sua forma- ção}

O estudante de licenciatura em Letras é preparado para atuar como docente em escolas de Educação Básica da rede pública ou privada de ensino. Espera-se dele que, ao final de sua formação, tenha adquirido todo o conhecimento necessário para atuação como profissional da educação. Essa formação deve ser ampla e oferecer ao professor em formação uma visão crítica das questões referentes à língua portuguesa e ao meio social.

A leitura aqui aparece como importante ferramenta no processo de formação do profissional de Letras. Ela permite o desenvolvimento de habilidades imprescindíveis para exercer a função de cidadão, dotado do conhecimento dos deveres e direitos. É por meio da leitura e da compreensão textual que se consegue entender a realidade, uma vez que a leitura de um texto precisa transcender os limites do próprio texto, remetendo o leitor à percepção e análise da realidade (SANTOS, 2006, p. 80).

\subsection{O profissional professor}

As condições de trabalho encontradas e a desvalorização social da profissão de professor são pontos de relevância que interferem diretamente na construção da identidade de futuros professores, uma vez que a identidade com a profissão diz respeito ao significado pessoal e social que a profissão tem para a pessoa. Se o professor perde o significado do trabalho, tanto para si próprio quanto para a sociedade, ele perde a identidade com a sua profissão.

A atividade profissional precípua de um professor é o ensino. Segundo Libâneo (2004), a formação inicial tem por objetivo propiciar conhecimentos, habilidades e atitudes para transmitir, nas escolas, o processo de ensino e aprendizagem adquiridos na graduação. Esse conjunto de requisitos que torna alguém professor é denominado profissionalidade. Ainda segundo o autor, o profissionalismo compreende o desempenho competente e compromissado dos deveres e das responsabilidades que abrangem a capacidade de ser professor, o que seria na prática o domínio dos métodos de ensino o respeito à diversidade, a dedicação ao trabalho, entre outras. 
Também necessária à formação docente, a profissionalização se refere à formação inicial e à formação continuada, em que o professor aprende e desenvolve as competências, habilidades e atitudes profissionais tendo em vista as condições de trabalho (recursos físicos e materiais e práticas de organização).

Souza (2006) afirma que a principal causa do fracasso e da baixa qualidade do sistema educacional brasileiro é a falta de preparo dos professores da educação básica:

Em função de sua má-formação inicial, os professores não saberiam como lidar com a diversidade de alunos presente nas escolas hoje, especialmente aqueles das camadas populares. Conseqüentemente, seguindo essa linha de raciocínio, a única, ou a principal ação a ser perseguida para melhorar a qualidade do sistema educacional, seria melhorar a competência dos professores (SOUZA, 2006, p.484).

O desenvolvimento dessa competência está presente no investimento na formação continuada dos profissionais da educação, mas não somente, uma vez que se fariam necessárias outras políticas educacionais mais abrangentes, que proporcionem condições concretas de trabalho nas escolas.

\section{Metodologia}

A metodologia utilizada neste estudo é a abordagem qualitativa. Essa perspectiva oferece maiores subsídios para o alcance dos objetivos específicos, por se tratar de uma pesquisa que necessita de uma visão detalhada do objeto em questão, além de oferecer maiores possibilidades de interpretação. Entretanto, para este trabalho utilizaram-se, também, dados quantitativos, uma vez que se considera que eles não constituem um entrave à adoção do modelo qualitativo.

Vilela Júnior (2010) afirma que a pesquisa qualitativa tem como objeto principal interpretar o fenômeno que se observa (a observação, a descrição, a compreensão e o significado). Não existem hipóteses pré-concebidas; essas hipóteses são construídas após a observação.

Foi utilizado, como instrumento de coleta de dados, um roteiro de entrevista semiestruturado, por combinar perguntas abertas e fechadas, o que permitiu um retorno rápido e possibilitou maior aprofundamento e esclarecimento das questões elaboradas.
Foram entrevistados estudantes do último semestre do curso de graduação em Letras de três instituições de ensino superior de Brasília, sendo 2 particulares e 1 pública. Esses estudantes assinaram um Termo de Conhecimento Livre e Esclarecido - TCLE, aceitando a sua participação na pesquisa e declarando estarem cientes de todas as informações referentes a ela, como o sigilo e o anonimato absolutos, a recusa em responder qualquer questão que lhe parecesse constrangedora e a sua retirada da pesquisa a qualquer momento.

\section{Resultado da análise e interpretação dos dados}

Os estudantes de graduação em Letras (formandos) demonstraram já ter tido contato com os vários "vieses" que a formação na área oferta, como a possibilidade de trabalhar com estrangeiros e o reforço escolar, além do estágio não-obrigatório. São estudantes que optaram pelo curso de licenciatura em Letras por possuírem identificação com o curso desde a Educação Básica, por gostarem de português, por terem tido bons professores entre outros fatores.

Esses formandos têm a pretensão de ser professores, mas ainda há algumas questões que ampliam o desestímulo, em que se destacam as condições que muitas escolas oferecem, como é o caso da rede pública de ensino. No entanto, encontram-se ainda aqueles que não pretendem seguir a carreira do magistério.

No que se refere aos hábitos de estudo desses acadêmicos, a realidade é apenas uma: o estudante não possui disciplina de estudo, o que demonstra certa desorganização de sua parte. Estudar só quando a disciplina da grade curricular é "muito pesada" é preocupante para o professor em formação. Nota-se ainda que o acadêmico de Letras não tem hábitos de estudo em grupo: geralmente ele não gosta dessa prática e quando estuda em grupo é porque há trabalhos que o exigem, não havendo outra saída. O parecer 09/2001 (BRASIL, 2010a) do CNE, alerta, inclusive, para questões como hábitos de colaboração e trabalho em equipe como obstáculo encontrado para formação do professor.

Ainda nesse cenário, outro dado encontrado refere-se às fontes de pesquisa para realização dos trabalhos acadêmicos. Todos os participantes indicaram a internet como a principal ferramenta de pesquisa. É sabida por 
todos a sua importância. A agilidade e eficiência são características que, no cotidiano tão corrido do cidadão, tornam mais viável a sua utilização. Porém, há o lado negativo quando o estudante não verifica se a fonte de sua pesquisa é realmente recomendável e realiza seu trabalho sem uma leitura reflexiva. Portanto, a internet é uma excelente ferramenta de pesquisa, desde que seja utilizada de maneira cautelosa.

Este estudo demonstrou, ainda, que estudantes de Letras afirmaram gostar de ler, no entanto, são contraditórios, pois registraram que leem, em geral, apenas os livros que são indicados como base para debates e avaliações na faculdade. Há registros do tipo: “[...] nunca li um livro por inteiro, só metade, ou partes. Para avaliação os professores nunca passam o livro todo, sempre uma parte específica [...]" (Estudante no 4 ).

Questionados a respeito da possibilidade de assumirem a sala de aula de Educação Básica, percebeu-se a identidade de um professor em formação com certa insegurança em relação ao cenário e ao cotidiano escolar. Nem mesmo o estágio curricular supervisionado ou outras práticas com a docência ofereceram a eles essas habilidades; pelo contrário, confirmaram algumas carências no processo de formação do profissional. Essas carências contemplam significativamente habilidades da componente prática pedagógica de sala de aula, uma vez que, em relação a conteúdos específicos, os dados são mais positivos.

Os participantes enfatizaram que a teoria para ser docente é bem transmitida no decorrer do curso, o que falta é a prática dessa teoria. Registraram que não saberiam lidar com o conteúdo específico e que a teoria adquirida não é aplicável em sala de aula. Há registros de que o aprofundamento na teoria objetiva direcionar o aluno à pesquisa, mesmo o curso sendo de licenciatura.

Indisciplina, sexualidade e drogas são alguns dos muitos problemas da escola, problemas esses delicados de se abordar, considerando que requerem domínio e conhecimento de suas origens. Por isso, o professor hoje não pode mais ser somente transmissor, mas deve, sobretudo, adotar o papel de educador, concepção que abrange muito mais do que o fato de ensinar. É nesse aspecto que se percebe pouquíssima preparação daquele que é o ator principal do processo de ensino/aprendizagem na escola. Os registros encontrados mostraram que o estudante de Letras não tem preparo quando o assunto são os proble- mas de sala de aula. Alguns notificam que têm postura, mas admitem que não saberiam como administrar questões como drogas, Transtorno de Déficit de Atenção com Hiperatividade (TDAH) e limitações físicas.

Quando inquiridos sobre se saberiam elaborar um plano de aula e um plano de ensino, por exemplo, as respostas, na grande maioria, foram "sim". No entanto, quando indagados e acerca de como fazer um plano de aula elencando habilidades e competências, notou-se grande insegurança dos participantes. Alguns não conseguiram se expressar e outros, mesmo conseguindo se expressar, se embaraçaram na compreensão de habilidades e competências.

Com referência à formação continuada, os participantes foram seguros ao responder que pretendem investir na continuação dos estudos, motivados pela crença de que o profissional deve estar sempre atualizado com as novidades de sua área de atuação, além do fato de que a maior qualificação reflete na produtividade em sala de aula. Apenas um participante respondeu não ter a pretensão de investir na continuação da formação, pois não tem interesse em atuar na área.

Por isso, fica evidenciado que os desafios para a formação de professores são grandes, sendo uma questão que envolve desde o tratamento inadequado dos conteúdos até a falta de prática pedagógica da academia. Reduzir o tempo de duração das licenciaturas não é um atrativo para os vestibulandos; pelo contrário, só acarretará máqualificação dos profissionais que estão sendo formados e “jogados” em sala de aula. O caminho poderia ser mais investimento na educação brasileira, o que compreende formação inicial e continuada de professores; melhores salários para atrair e motivar os professores; boa qualidade de ensino nas escolas (recursos didáticos, espaço físico) entre outros.

\section{Considerações finais}

Este trabalho evidenciou um estudante de Letras com relativo envolvimento com a universidade, comprovado pelos dados que indicaram a pouca participação em atividades extraclasse e um nível baixo de leitura, considerando que são realizadas apenas as leituras solicitadas pela academia.

O grupo analisado compôs-se de formandos em Letras (licenciatura), dos quais metade já teve experiência 
nas áreas que o curso possibilita (trabalho com estrangeiros, aulas particulares, reforço escolar e estágios nãoobrigatórios). No entanto, o que se nota de interessante - apesar das experiências relatadas - é a pouca familiaridade com o ambiente escolar. Aqueles que já tiveram essa experiência relatam que puderam perceber o quanto é falha a parte prática de sua formação.

Nesse aspecto, nota-se um formando inseguro em relação a assumir uma sala de aula e que demonstra certa limitação em assuntos práticos, como planejamento de aula, resolução de problemas internos (trabalho com indisciplina, sexualidade) e a falta de conscientização, por exemplo, para defender as causas relacionadas à valorização da educação brasileira.

Pode-se perceber, ainda, que a relação de teoria e prática é muito deficitária. Os dados mostraram uma formação basicamente teórica, que não é voltada para a prática. Os cursos oferecem disciplinas como Didática, mas geralmente essas disciplinas são ministradas em turmas compostas por alunos de diversos cursos de graduação, o que impossibilita um trabalho mais específico com a prática do conteúdo de determinada área do ensino.

Propiciar uma formação que conjugue teoria e prática, responsabilidade social, abordagem adequada de conteúdos e conscientização acerca da importância do professor para a sociedade são aspectos que valorizam o docente como principal personagem do processo de ensino/aprendizagem. Bem formado, esse profissional terá condições de também formar cidadãos com visão ampla e atuante nas práticas sociais.

\section{Referências}

BENEVIDES, Araceli Sobreira. A formação de professores do curso de Letras: aspectos para uma prática reflexiva. Revista Eletrônica de Divulgação Científica em Língua Portuguesa, Lingüística e Literatura, Natal, ano 3, n. 5, p.1-19, jul./dez. 2006. Disponível em: <http://www. letramagna.com/formacaoprof2.pdf $>$. Acesso em: 16 abr. 2010.

BRASIL. Ministério da Educação. Parecer nº 009/2001. Diretrizes Curriculares Nacionais para formação de professores da Educação Básica, em nível superior, curso de licenciatura, de graduação plena. Brasília, 2001a. Disponível em: <http://www.uems.br/proe/sec/ Parecer\%2 0CNE-CP\%20009-2001.pdf>. Acesso em: 19 abr. 2010.

BRASIL. Ministério da Educação. Parecer no 492/2001. Diretrizes Curriculares Nacionais dos cursos de Filosofia, História, Geografia, Serviço Social, Comunicação Social, Ciências Sociais, Letras, Biblioteconomia, Arquivologia e Museologia. Brasília, 03 de abril de 2001b Disponível em: <http://portal.mec.gov.br/cne/arquivos/pdf/CES0492. pdf>. Acesso em: 25 abr. 2010.

LIBÂNEO, José Carlos. Organização e gestão da escola: teoria e prática. Goiânia: Alternativa, 2004.

MAGISTÉRIO: prestígio zero. Revista Veja, São Paulo, ano 43, n.6, p. 87, 10 fev. 2010. Disponível em: <http:// veja.abril.com.br/noticia/brasil/magisterio-prestigiozero-531806.shtml>. Acesso em: 18 abr. 2010.

SANTOS, Silmara de Jesus Bignardi dos. A importância da leitura no Ensino Superior. Revista de Educação. v. 9, n.9, p. 77-83, 2006.

SOUZA, Denise Trento Rebello de. Formação continuada de professores e fracasso escolar: problematizando o argumento da incompetência. Educação e Pesquisa, São Paulo, v. 32, n. 3, p. 477-492, set./dez., 2006.

VILELA JUNIOR, Guanis de Barros. Pesquisa qualitativa. Disponível em: <http://www.guanis.org/metodologia/a_ pesquisa_qualitativa.pdf $>$. Acesso em: 18 abr. 2010. 